\title{
Hydrogen Re-Embrittlement of Aerospace grade High Strength Steels
}

\author{
R. Valentini, C. Colombo, M. De Sanctis, G. Lovicu \\ Department of Chemical Engineering, University of Pisa, Pisa (Italy) \\ r.valentini@diccism.unipi.it
}

\begin{abstract}
Hydrogen Re-Embrittlement on anodically coated high strength steels is a relevant risk for aerospace structures due to the possibility of hydrogen uptake during the operative life of the components. AISI 4340 and Maraging 250 unnotched tensile specimens were subjected to SSRT in order to evaluate the influence of test environment on time to failure. Fracture surfaces were examined by SEM analysis to evaluate the degree of embrittlement and to correlate it with hydrogen diffusivity of the tested steels.
\end{abstract}

SOMMARIO. Il Re-Infragilimento da idrogeno di acciai altoresistenziali con rivestimenti sacrificali anodici è un rischio concreto per le strutture aerospaziali a causa della possibilità che si verifichi l'assorbimento di idrogeno durante la vita operativa dei componenti. Per valutare l'influenza dell'ambiente sul tempo a rottura, sono state svolte prove SSRT con provini di trazione lisci realizzati in AISI 4340 e Maraging 250. Le superfici di frattura sono state esaminate al SEM per valutare il grado di infragilimento e correlarlo con la diffusività dell'idrogeno degli acciai testati.

KEYwORDS. Hydrogen Re-Embrittlement; AISI 4340; Maraging 250; High Strength Steels; Bolt failure.

\section{INTRODUCTION}

7 his work falls within the context of brittle fractures associated to hydrogen embrittlement for anodically high strength steels (HSS) widely used in the aerospace field. Concerning environment induced failures, HRE is the most dangerous attack for anodically coated HSS components because, differently from Hydrogen Embrittlement (HE), HRE is an irreversible phenomenon that can't be avoided by means of preventive degassing. As a matter of fact, if the protective surface coating is damaged, localized corrosion may lead to embrittlement during its service. Regarding aerospace structures, the risk for HRE is relevant in bolt thread regions, where the coating is likely to be mechanically scratched during assembling. Therefore, the exposed steel becomes the cathodic area of the corrosion reaction and hydrogen reduction takes place on it. Once atomic hydrogen enters the steel, it diffuses toward regions of high stress states, and depending on the aqueous environment corrosivity and on the material hydrogen embrittlement susceptibility, the steel component could suffer for brittle cracking. This article presents the results of the second experimental activity inspired by the failure of a Cd-plated AISI 4340 steel bolt coupled with a IN718 nut due to HRE. Thanks to the first work[1], it was demonstrated that, in presence of a crevice, metals nobler than cadmium strongly enhance local hydrogen reduction on exposed steel areas. The susceptibility of anodic coated HSS to HRE, if loaded in the above mentioned environments, has been largely proved with different kind of anodic coatings[2-4]. Conversely, Maraging steels resistance to HRE hasn't been characterized yet. The aim of this experimental campaign is comparing the resistance of Maraging 250 to AISI 4340 as far as HRE susceptibility is concerned. 


\section{EXPERIMENTAL PROCEDURES}

wo series of Maraging specimen were heat treated to achieve the desired resistance, the first was peak-aged at $480^{\circ} \mathrm{C}$ for 8 hours and the second at $535^{\circ} \mathrm{C}$ for 1 hour. AISI 4340 was quenched and tempered to achieve a hardness of 50-52 HRC. The mechanical properties of the materials in exams are presented in Table 1.

\begin{tabular}{cccc}
\hline Material & $\begin{array}{c}\boldsymbol{\sigma}_{\mathbf{Y}} \\
{[\mathrm{MPa}]}\end{array}$ & $\begin{array}{c}\boldsymbol{\sigma}_{\mathbf{U}} \\
{[\mathrm{MPa}]}\end{array}$ & $\mathbf{H V}_{\mathbf{2 0}}$ \\
AISI 4340 & 1548 & 1858 & 549 \\
Maraging 250 (peak-aged at $480^{\circ} \mathrm{C}$ ) & 1720 & 1740 & 509 \\
Maraging 250 (peak-aged at $535^{\circ} \mathrm{C}$ ) & 1400 & 1410 & 441 \\
\hline
\end{tabular}

Table 1: Average (3 specimens) yield $\left(\sigma_{\mathbf{Y}}\right)$ and ultimate strength $\left(\sigma_{\mathbf{U}}\right)$ for SSRT tested steels.

Cylindrical unnotched specimens ( $3 \mathrm{~mm}$ of diameter and $25 \mathrm{~mm}$ of gage) were used for HRE tests. Specimens were anodically coated with a layer of Zinc $(15 \mu \mathrm{m})$ as visible in Fig. 1 (a) to obtain a high current associated to hydrogen reduction. To expose the underlying steel, Zinc was removed from an annular area (1 mm wide) shown in Fig. 1 (b). Mechanical tests (SSRT at a strain rate of $3.3 \cdot 10^{-5} \mathrm{~s}^{-1}$ ) were performed in the following conditions: air, $3.5 \% \mathrm{NaCl}$ aqueous solution and paint-stripper. Further tests in salt solution were conducted with the addition of a galvanic coupling to recreate the enhancing effect of a nobler material on HRE. For this particular test, the coupling was made of AISI 316 (austenitic stainless steel), for its high galvanic activity and its good availability and workability. The coupling was made in two symmetrical halves and designed with a cylindrical cavity with the same nominal diameter of the specimen. Specimen and coupling were assembled like shown in Fig. 1 (c) to provide a suitable crevice for HRE.
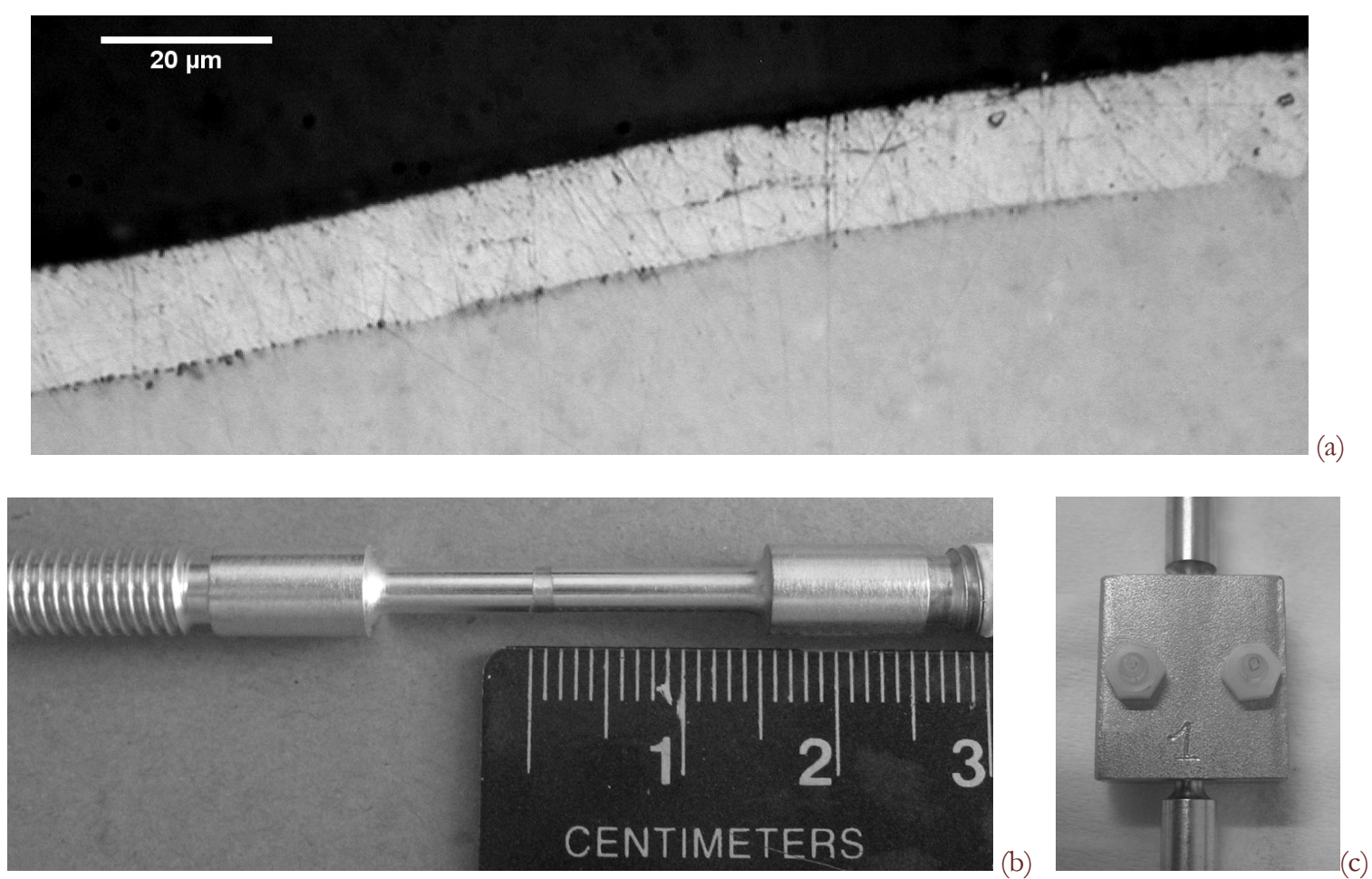

Figure 1: (a) Optical microscope picture of Zinc layer (500X), (b) Zinc coated round unnotched tensile specimen with the annular exposed steel area and (c) galvanic coupling made of AISI 316. 


\section{RESULTS}

$\mathrm{R}$ esults of SSRT campaign are presented, as a function of time to failure and environment, in Table 2. Figures 2 to 3 show the measured stress as a function of time for the AISI 4340 and Maraging 250 respectively. From the curves of Fig. 3, it emerges as the shortest time to failure for AISI 4340 (551 s compared to $2490 \mathrm{~s}$ of the specimens loaded in air) was measured for the specimens subjected to painting and then stripped. Specimens, tested in salt solution, with and without galvanic coupling failed in comparable times. In particular, the specimens coupled to AISI 316 failed inside the galvanic coupling, even if externally to the exposed area. Fig. 4 (a) shows both the absence of necking and the ring of zinc corrosion products for one of the specimens involved in the latter test. Regarding Maraging 250, any of the curves related to the specimens loaded in corrosive environment differed significantly from the trend associated to the test performed in air. In detail, time to failure for Maraging peak-aged at $480^{\circ} \mathrm{C}$ were approximately equivalent in all the conditions, whereas the curves related to the Maraging peak-aged at $535^{\circ} \mathrm{C}$ differed slightly both for time to failure and sustained load. Furthermore, it was observed that all Maraging 250 specimens presented ductile necking like the one showed in Fig. 4 (b). Results from scanning electron in microscopy (SEM) analysis are shown in Figures 5 to 10 for the most significant tests. According to fracture surfaces of Fig. 5, test in air for AISI 4340 resulted in a ductile rupture. Conversely, Fig. 6 displays a brittle fracture for AISI 4340 specimens loaded after paint-stripper application. SEM analysis on Maraging 250 surface fractures confirmed what was visible at naked eye in Figure 4 (b), that is all the specimens failed with a cup-cone fracture as visible in Figures from 7 to 9 independently of the test environment.

\begin{tabular}{c|cccc}
\hline \multirow{2}{*}{ Material } & \multicolumn{4}{c}{ Time to failure $[\mathrm{s}]$} \\
& Air & $3.5 \% \mathrm{NaCl}$ & $\begin{array}{c}3.5 \% \mathrm{NaCl}+ \\
\text { coupling }\end{array}$ & $\begin{array}{c}\text { Paint- } \\
\text { stripper }\end{array}$ \\
\hline AISI 4340 & 2490 & 607 & 675 & 551 \\
Maraging 250 (peak-aged at $480^{\circ} \mathrm{C}$ ) & 1833 & 1687 & 1737 & 1745 \\
Maraging 250 (peak-aged at $535^{\circ} \mathrm{C}$ ) & 3563 & 4175 & 2940 & 3100 \\
\hline
\end{tabular}

Table 2: Average (3 specimens) example of measured time to failure for SSRT conducted on the three materials loaded in different environments.

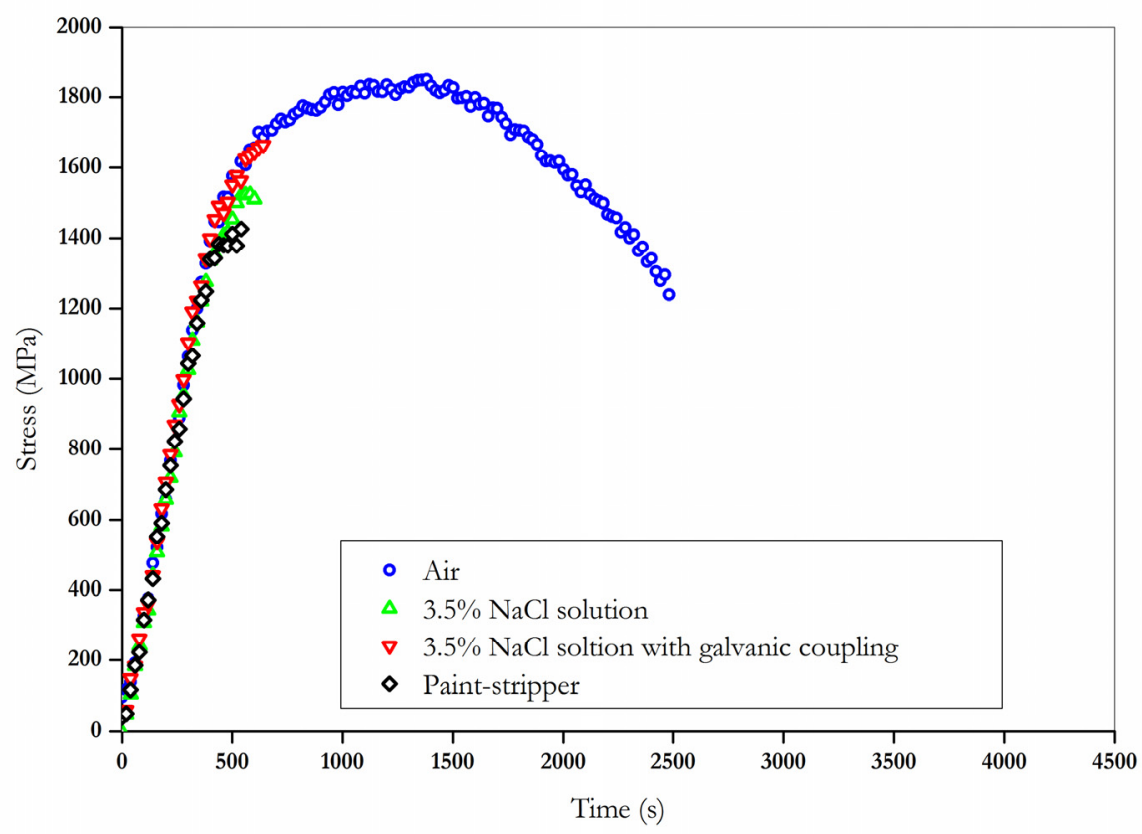

Figure 2: Stress-Time to Failure curves for AISI 4340. 


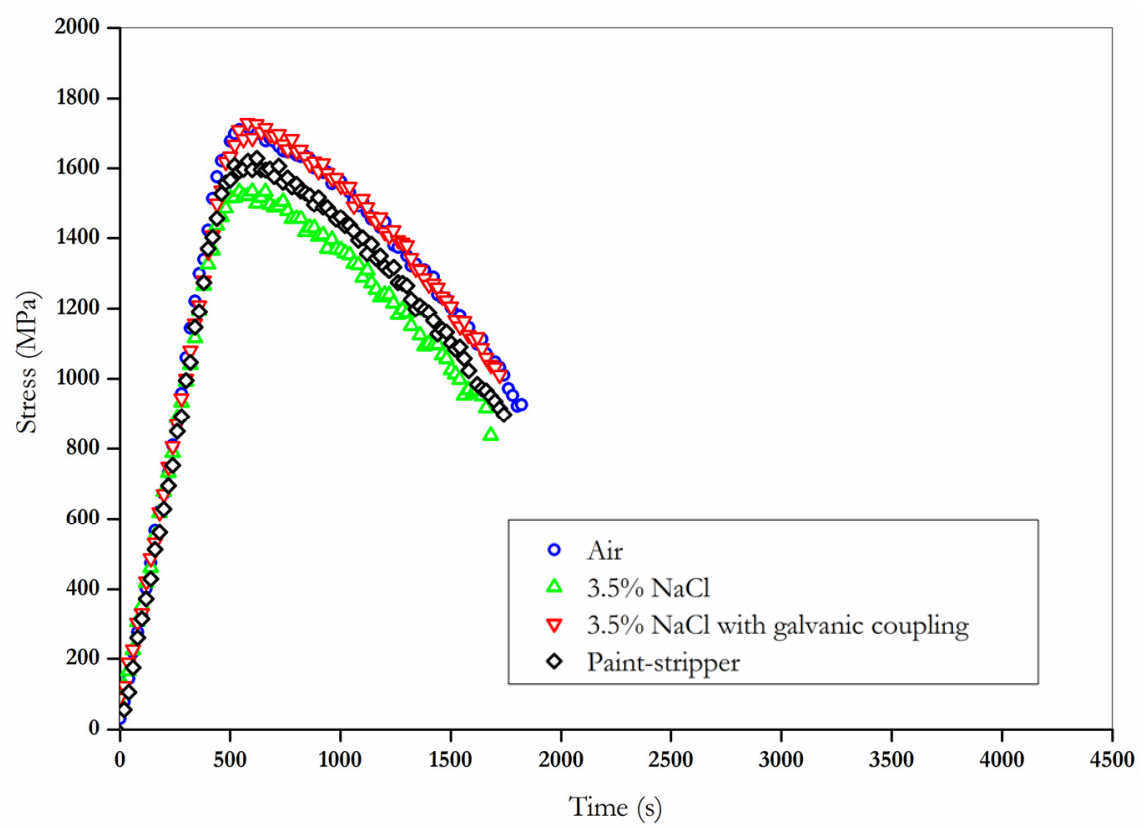

(a)

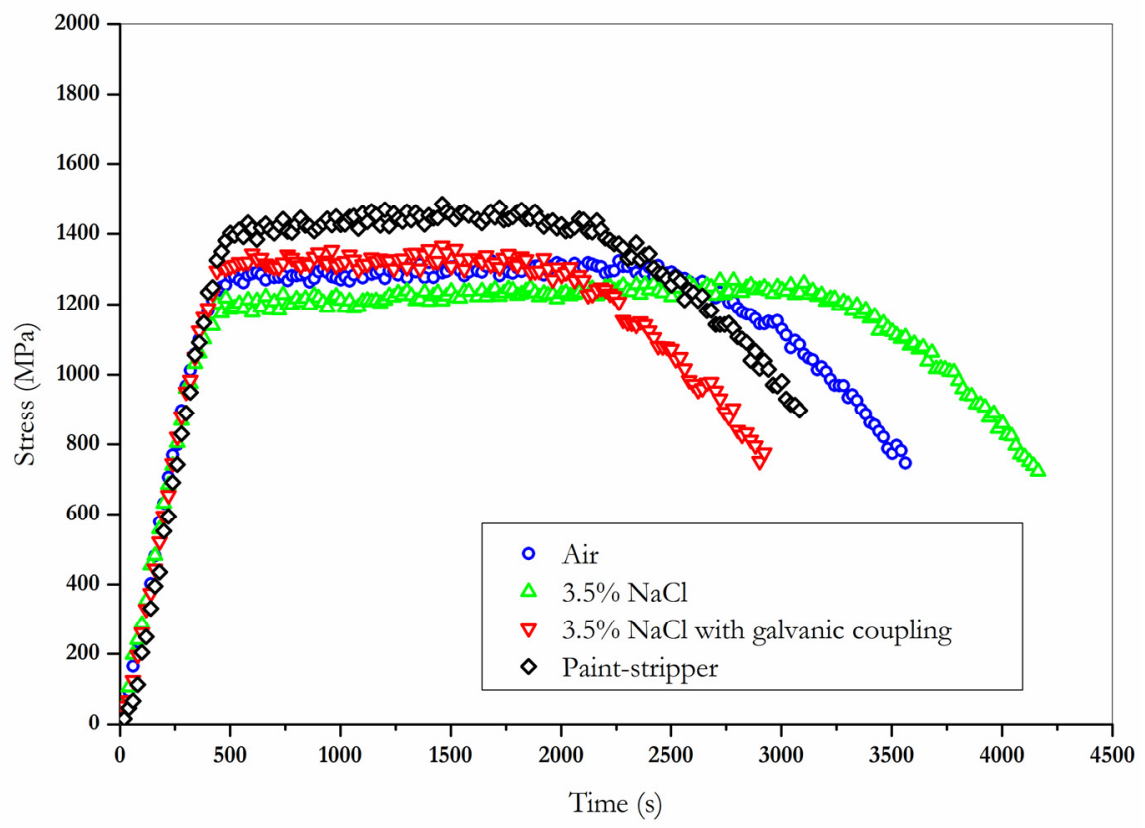

Figure 3: Stress-Time to Failure curves for Maraging peak-aged at $480^{\circ} \mathrm{C}$ (a) and at $535^{\circ} \mathrm{C}$ (b).
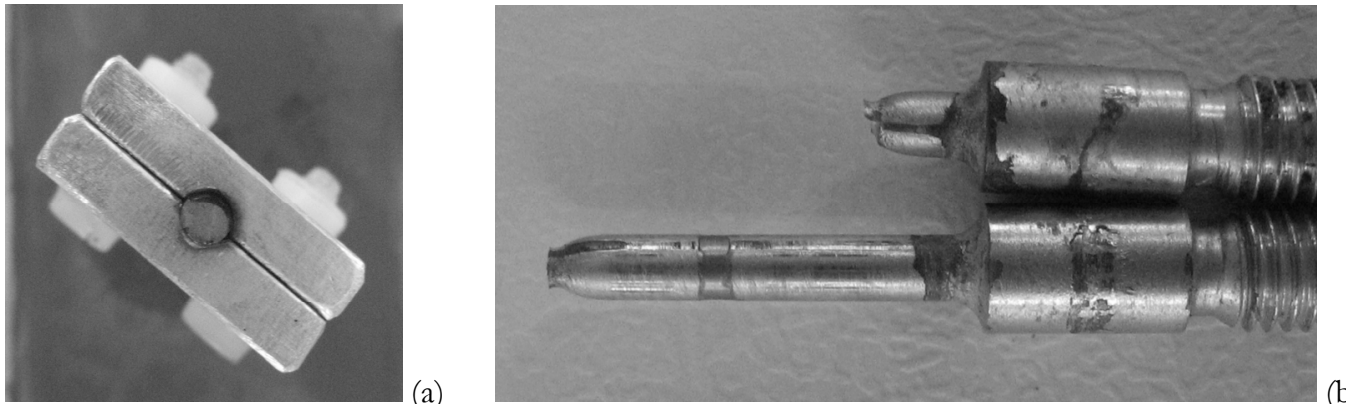

(b)

Figure 4: (a) Appearance of AISI 4340 specimen after SSRT coupled to AISI 316 and immersed in $\mathrm{NaCl} 3,5 \%$ aqueous solution and (b) Maraging 250 peak-aged at $480^{\circ} \mathrm{C}$ specimen. 

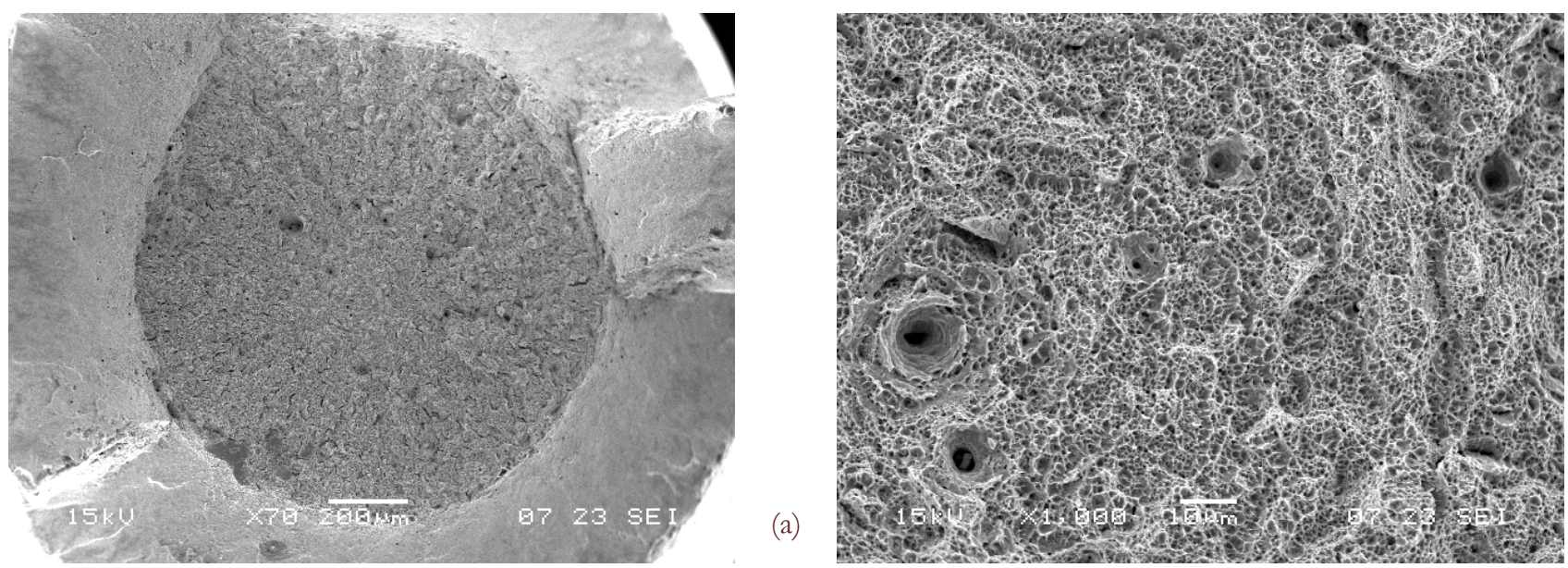

Figure 5: (a) Fracture surface for AISI 4340 specimen and (b) X1000 magnification for test in air.
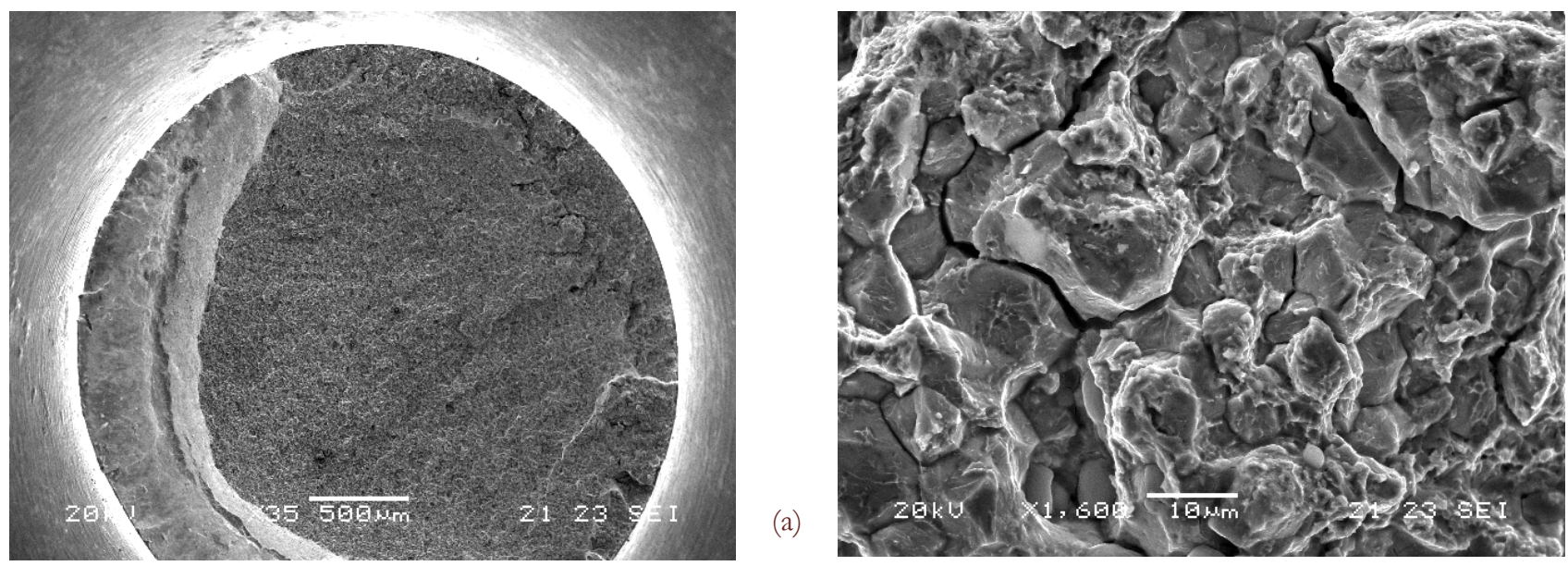

Figure 6: (a) Fracture surface for AISI 4340 specimen and (b) X1000 magnification for test with paint-stripper.
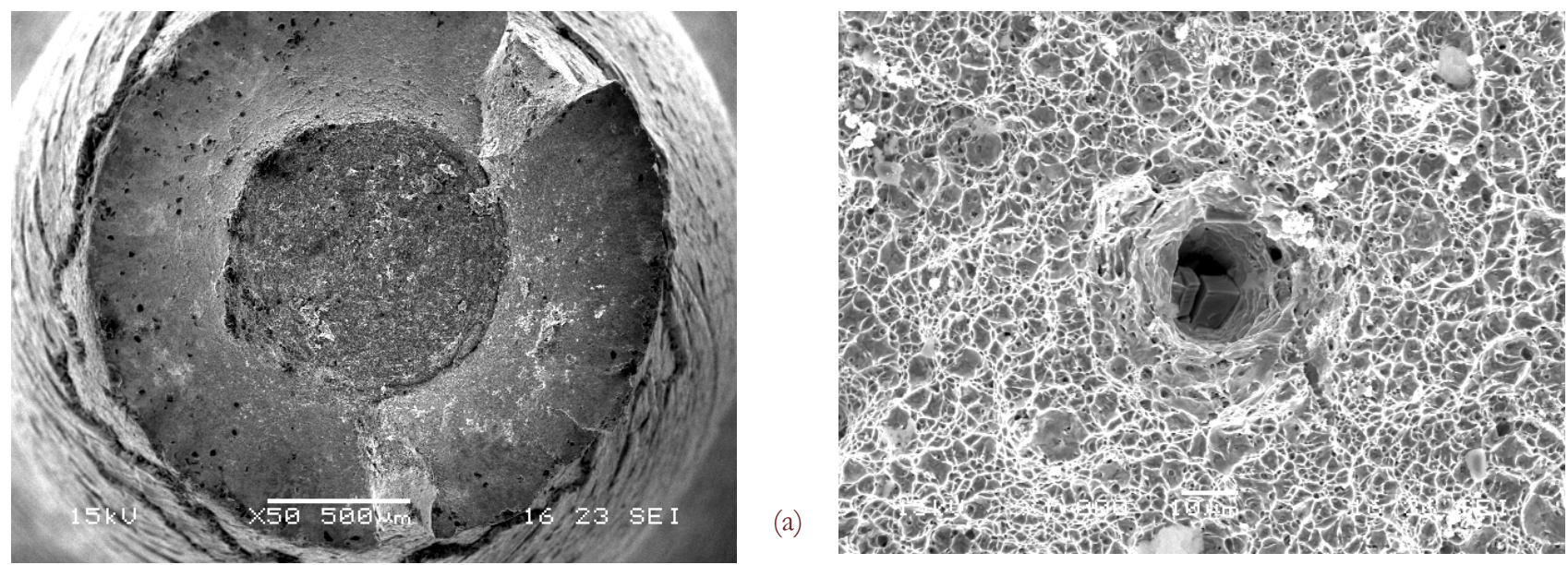

(b)

Figure 7: (a) Fracture surface for Maraging 250 specimen peak-aged at $480^{\circ} \mathrm{C}$ and (b) $\mathrm{X} 1000$ magnification for test in $3.5 \% \mathrm{NaCl}$ aqueous solution with galvanic coupling. 

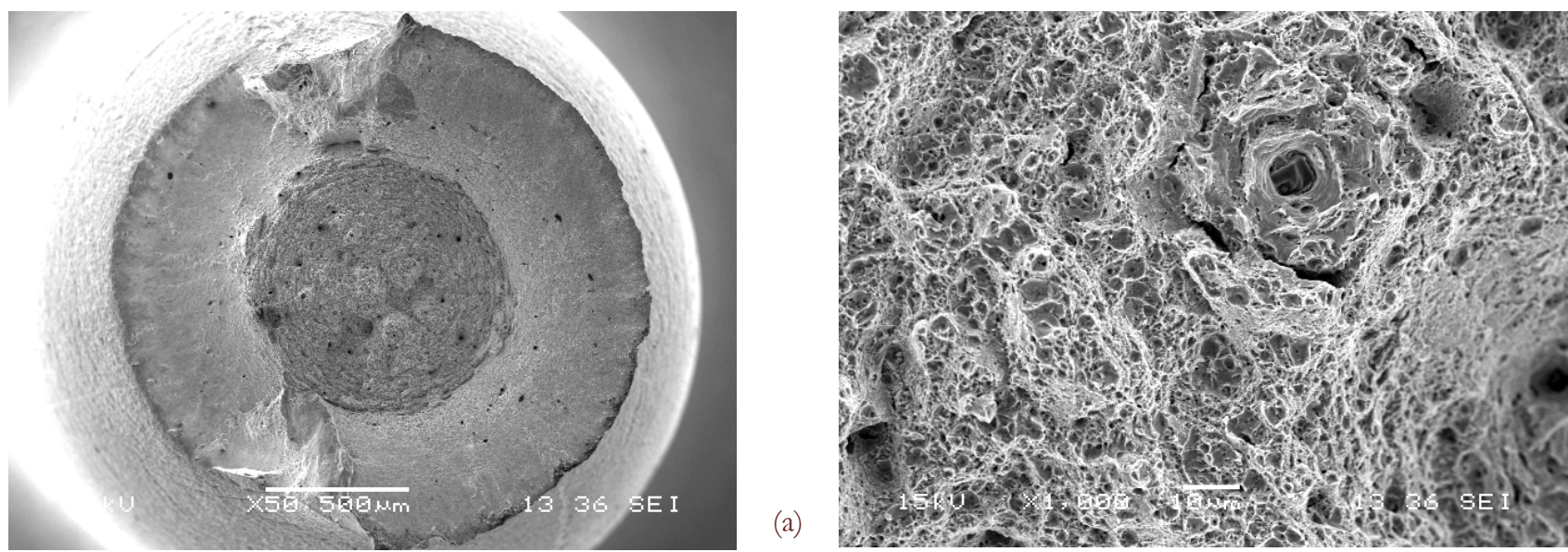

Figure 8: (a) Fracture surface for Maraging 250 specimen peak-aged at $535^{\circ} \mathrm{C}$ and (b) $\mathrm{X} 1000$ magnification for test in air.
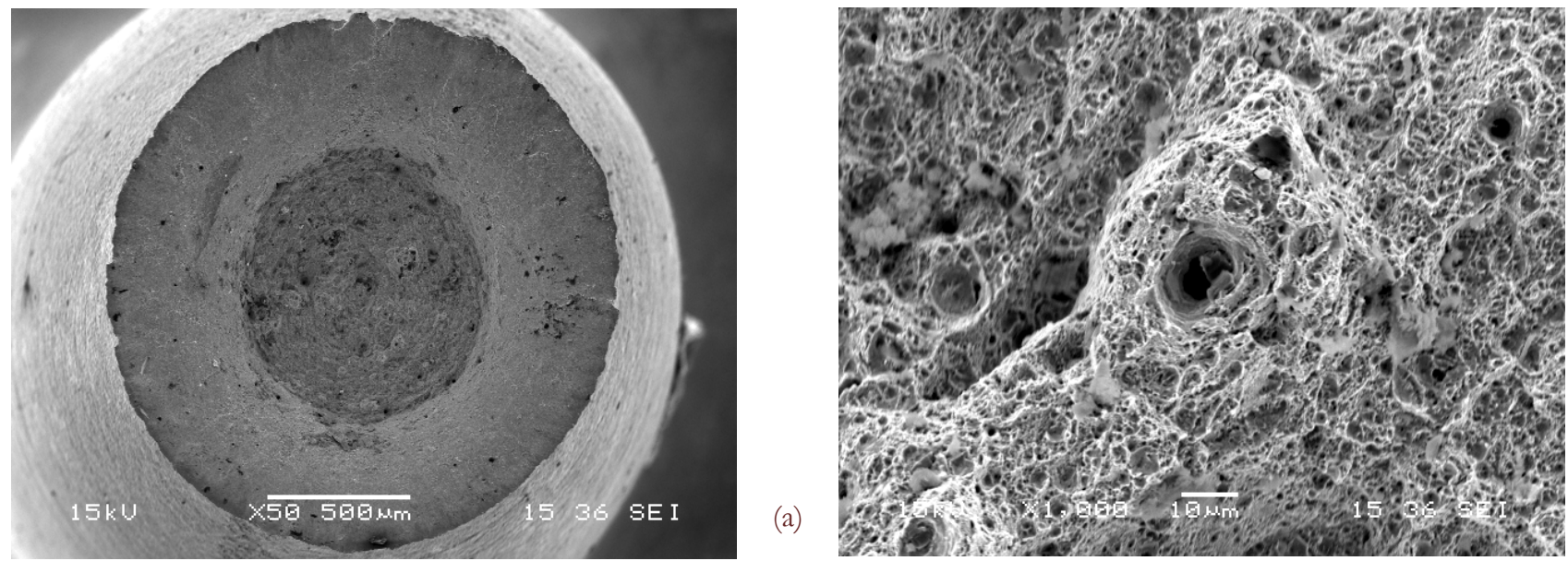

(b)

Figure 9: (a) Fracture surface for Maraging 250 specimen peak-aged at $535^{\circ} \mathrm{C}$ and (b) $\mathrm{X} 1000$ magnification for test in $3.5 \% \mathrm{NaCl}$ aqueous solution with galvanic coupling.

\section{Discussion}

$\mathrm{E}$ xperimental evidence for AISI 4340 confirms severe re-embrittlement when the steel is subject to hydrogen uptake. As expected, only test in air resulted in a ductile fracture whereas the others environments, chosen for their high conductivity for HE[5-9], lead to brittle fractures in approximately one fifth of time. Test results for Maraging 250 proved that any of the grades suffered from the embrittling effect of the corrosive environments, neither in the most severe conditions, that is coupling to AISI 316 and paint-stripper. Comparing Figure 3 (a) to 3 (b) it is clear as Maraging peak-aged at $535^{\circ} \mathrm{C}$ exhibits a greater percent elongation than the steel in its original condition (peak-aged at $480^{\circ} \mathrm{C}$ ). Difference is due both to the lower yield strength and the possible higher content of reversion austenite. The lack of uniformity for SSRT performance of Maraging peak-aged at $535^{\circ} \mathrm{C}$ may be attributed to non homogeneous heat treatment conditions for the specimens treated in Laboratory. Regarding SEM analysis, it's worth noting the difference between the fracture in air for AISI 4340 (Fig. 5) and that related to the specimen loaded in after paint-stripper application (Fig. 6). In the first case, the material displays a ductile aspect with an external ring associated to the first phase of necking and a more fibrous core better shown in Figure 5 (b). For the second case, Fig. 6 (b) shows intergranular fractures due to hydrogen uptake inside the growing crack[10]. As previously stated, Maraging fractures follow the classical cup-cone model for ductile necking. From pictures taken at higher magnification (Figures from 7 to 9) it can be noticed as the presence of precipitates had influenced the modality of rupture. These formations, probably Titanium nitrides, formed 
during the heat treatment phase at high temperature, create discontinuity in the metallic matrix. Due to this, matrix decohesion is eased around the precipitates and larger dimples occur. In particular, in Fig. 7 (b) is shown a precipitate fractured in three parts. As far as diffusivity of hydrogen in HSS is concerned, all the materials involved in this study were previously characterized using a Devanathan-Stachurski[11] permeation apparatus. The highest value is related to AISI (is $\left.1 \cdot 10^{-7} \mathrm{~cm}^{2} / \mathrm{s}\right)$ whereas diffusion in both grades of Maraging 250 is an order of magnitude lower $\left(8.20 \cdot 10^{-9} \mathrm{~cm}^{2} / \mathrm{s} \mathrm{for} \mathrm{peak-}\right.$ aged at $480^{\circ} \mathrm{C}$ and $9.58 \cdot 10^{-9} \mathrm{~cm}^{2} / \mathrm{s}$ for peak-aged at $535^{\circ} \mathrm{C}$ ) [12]. Known the diffusion coefficient of hydrogen in the steel, it is possible to calculate the distance at which hydrogen concentration is about $50 \%(X)$ inside the metallic matrix, during the test duration, by the following formula [13]

$$
X=2 \sqrt{D t}
$$

where $D$ is the diffusion coefficient in $\mathrm{cm}^{2} / \mathrm{s}$ and $t$ is the time in seconds. Referring to SSRT curves presented in Figures 4 and 5 , it is reasonable to take $500 \mathrm{~s}$ as average duration of hydrogen diffusion through the steel. By calculation, it is obtained a length of penetration of $140 \mu \mathrm{m}$ and about $40 \mu \mathrm{m}$ for AISI 4340 and Maraging 250 respectively. Initiation area for fractures shown in Figure 6 is congruent with the order of magnitude of hydrogen penetration through AISI 4340. Even the result for Maraging is consistent with its experimental evidence, because such a low value of penetration through the steel could not enhance its embrittlement. In conclusion, SSRT duration results insufficient to start HRE for Maraging 250. In order to obviate this problem, other tests may be conducted with a strain rate of an order of magnitude lower or by constant load tensile test of standard duration (200 h maximum) [14].

\section{CONCLUSIONS}

$\checkmark$ AISI 4340 exhibited a relevant susceptibility to HRE whereas both grades of Maraging 250 appeared immune to the phenomenon in the present experimental conditions.

$\checkmark$ Fracture surface analysis by SEM is consistent to hydrogen depth of penetration model both for AISI 4340 and Maraging 250.

$\checkmark$ SSRT duration is too short to enhance brittle cracking of Maraging 250, further test must be conducted to deepen the knowledge of influence of HRE for this class of steel.

$\checkmark$ Maraging 250 peak-aged at $535^{\circ} \mathrm{C}$ showed a higher percent elongation than the grade peak-aged at $480^{\circ} \mathrm{C}$.

\section{REFERENCES}

[1] G. F. Lovicu, C. Colombo, M. De Sanctis, R. Valentini, Met. Trans. A, 42 (2011) 3577.

[2] G. Chalaftris, M.J. Robinson, Corr. Eng. Sci. Tech., 40 (2005) 28.

[3] D.J. Figueroa Gordon, Ph.D. Dissertation, Cranfield University, Cranfield, UK, (2005).

[4] D. Figueroa, M.J. Robinson, Corr. Sci., 50 (2008) 1066.

[5] E. E. Nelson, T. S. Humphries, J. R. Lowery, NASA, MSFC Memorandum EH24 (1981).

[6] R. P. Gangloff, Hydrogen Assisted Cracking Of High Strength Alloys, Elsevier Science, (2003) 31.

[7] W. J. Pollock, Prevention and Control ASTM STP 962, L. Raymond Ed., ASTM, Philadelphia, (1988) 372.

[8] R. M. Nageswara, Corr. Sci., 51 (2009) 1645.

[9] J. C. Scully, NATO Scientific Affairs Division, (1971).

[10] P. Novak, R. Yuan, P. Somerday, P. Sofronis, R. O. Ritchie, Journal Mech. Phys. Solids, 58 (2010) 206.

[11] M.A.V. Devanathan, Z. Stachurski, Proc. R. Soc. London, Ser. A , 270 (1962) 90.

[12] R. Lontano, Bachelor Dissertation, University of Pisa (2011)

[13] J. Crank, The Mathematics of Diffusion, Oxford University Press (1975)

[14] ASTM F 519 Standard test method for Mechanical Hydrogen Embrittlement Evaluation of Plating/Coating Processes and Service Environments. 